\title{
MOLECULAR DOCKING AND SCREENING OF DRUGS FOR 6LU7 PROTEASE INHIBITOR AS A POTENTIAL TARGET FOR COVID-19
}

\author{
MANOJ GADEWAR ${ }^{1}$, BHARAT LAL ${ }^{2}$
}

1Department of Pharmacology, K. R. Mangalam University, Gurugram, Haryana, India, ${ }^{2}$ Department of Pharmaceutics, K. R. Mangalam University, Gurugram, Haryana, India

Email: manojgadewar@gmail.com

Received: 14 Sep 2021, Revised and Accepted: 25 Oct 2021

\section{ABSTRACT}

Objective: The aim of present investigation is docking of various existing antiviral, anti-tubercular and anti-malarial drugs on 6LU7 receptor of SARS-CoV-2 in the treatment of COVID-19.

Methods: In this study, the structure of coronavirus binding protein and ligands for various drugs were collected from the protein data bank and pub chem. Molecular docking was carried out using Schrodinger 9.0 software. In molecular docking study, 19 different drugs of various categories like antiviral, anti-malarial and anti-tubercular were investigated for analyzing binding to 6LU7 receptors of COVID-19.

Results: The docking result showed a high affinity of zanamivir, montelukast, ramdesvir, ritonavir, cobicistat and favipravir to the 6LU7 receptor of novel coronavirus. Thus the combination of these drugs may be useful in preventing further infection and can be used as a potential target for further in vitro and in vivo studies of SARS-CoV-2.

Conclusion: Treatment of COVID-19 has been challenge due to the non-availability of effective drug therapy. In this study, we reported drugs for targeting 6LU7 Mpro/3Clpro protein, which showed prominent effects as potential inhibitors of COVID-19 Mpro.

Keywords: COVID-19, RNA dependant RNA polymerase, Molecular docking, Antiviral, Anti-malarial

(C) 2022 The Authors. Published by Innovare Academic Sciences Pvt Ltd. This is an open access article under the CC BY license (https://creativecommons.org/licenses/by/4.0/) DOI: https://dx.doi.org/10.22159/ijap.2022v14i1.43132. Journal homepage: https://innovareacademics.in/journals/index.php/ijap

\section{INTRODUCTION}

Since December 2019, an epidemic of corona has been spreading all across the globe. China reported a case of pneumonia of unknown cause on 31st Dec 2019 in some patient operating in Huanan seafood market of Wuhan in Hubei province and caused outbreak of a novel corona (nCOVID-19). After genome analysis it was found that causative agent for the infection was zoonotic coronavirus and this novel Coronavirus (2019-nCoV) which resembles similarity with severe acute respiratory syndrome coronavirus (SARS-CoV) and Middle East Respiratory Syndrome coronavirus (MERS-CoV) but with fast transmission and rapid rate of infection. On 11 $1^{\text {th }}$ March 2020 WHO characterized COVID-19 outbreak is a pandemic and released interim guidelines on critical preparedness, readiness and response actions to keep people safe from the COVID-19 [1, 2].
Due to the characteristic appearance of crown-like spikes around the virion it is renamed as corona virus. Coronaviruses belongs to the sub family Orthocoronavirinae, of the family Coronaviridae, order Nidovirales. Coronaviruses are spherical-shaped viruses having size around $120 \mathrm{~nm}$ diameters. These are lipid bilayered viruses consist of membrane (M), envelope (E) and spike (S) structural proteins. Inside the envelope it contains nucleocapsid formed from multiple copies of the nucleocapsid (N) protein, which are anchored with a positive-sense singlestranded RNA genome in a continuous beads-on-a-string type conformation. The genome size of coronaviruses is largest among RNA viruses which ranges approximately from 27 to 34 kilobases 3 and it has a $5^{\prime}$ methylated cap and a $3^{\prime}$ polyadenylated tail fig. 1 [3].

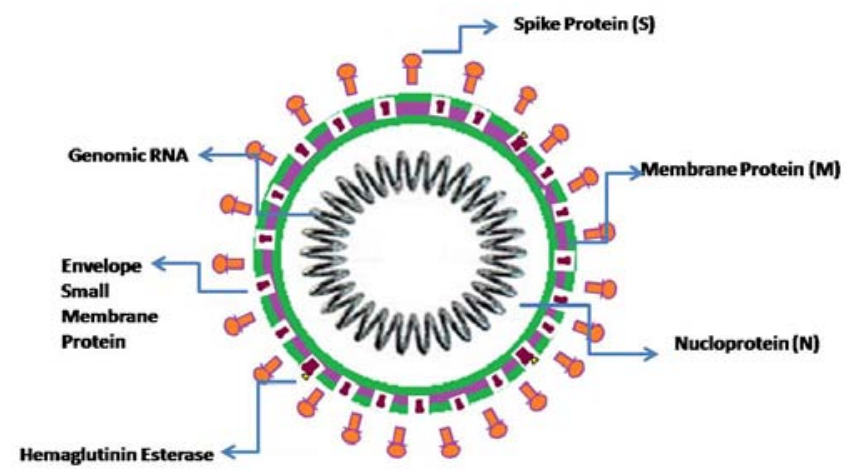

Fig. 1: Structure of COVID-19

Genetically they are classified into four major genera Alpha, Beta, Gamma, and Delta coronavirus; the former two genera primarily infect mammals, whereas the latter two predominantly infect birds. Six kinds of human coronavirus have been previously identified, which include HCoV-NL63 and HCoV229E (Alpha coronavirus) and
HCoV-OC43, HCoVHKU1, SARS-CoV, MERS-CoV (Beta coronavirus) and COVID-19 is seventh [4].

The life cycle of COVID-19 begins in host cells once it reaches to lungs and binds to the type-II pneumocytes of the alveoli using its 
spike proteins (S protein) to the cellular receptor Angiotensin converting enzyme-2 (ACE-2). After binding to the receptor, conformational changes in the $S$ protein facilitates viral envelope fusion with the cell membrane through the endosomal pathway. Following fusion with host cells, virus injects its positive single stranded RNA (+ssRNA) into a host cell which then translates into viral replicase polyproteins pp1a and $1 \mathrm{ab}$ and results in to cleavage to small products by viral proteinases. The polymerase produces a series of sub-genomic mRNAs by discontinuous transcription and finally translated into relevant viral proteins. Host RNA-dependent RNA polymerase converts the viral RNA into a new virions genome. Viral proteins and genome RNA are subsequently assembled into virions in the endoplasmic reticulum and Golgi apparatus and then transported via vesicles and released out of the cell fig. 2 [5].

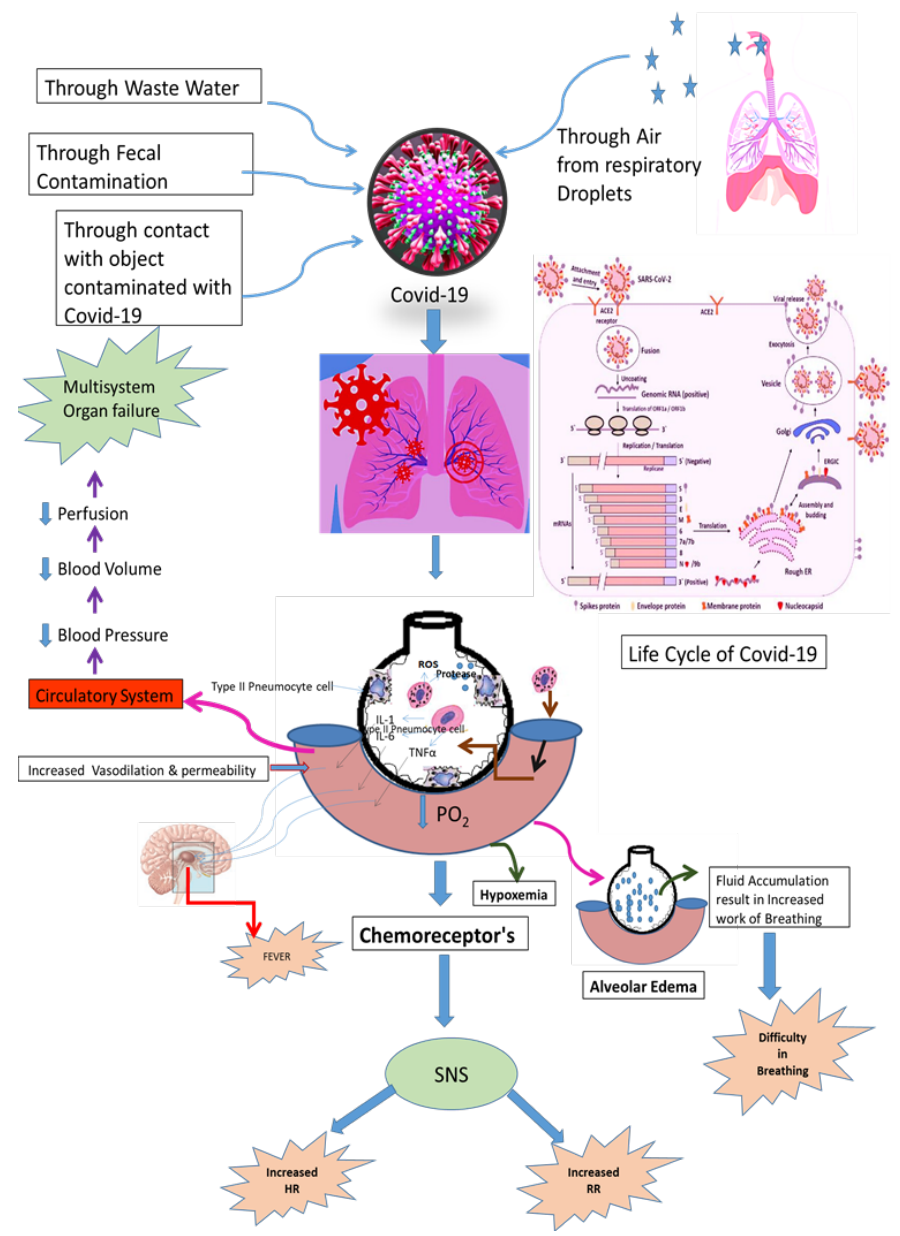

Fig. 2: Life cycle of COVID-19

Healthy person get infected when they come in contact with infected person. Once at the surface, the virus reaches to alveolar type-2pneumocytes where it attaches with spike protein with ACE2 receptor of type- 2 cells. Following fusion with host cells, the virus injects its positive single-stranded RNA (+ssRNA) into host cell. Host cells, ribosomes translates the viral into large viral proteins which is further chopped into smaller proteins and used to make the structural proteins of progeny virions. Host RNA-dependent RNA polymerase converts the viral RNA into new virions genome. Progeny virus, after completing the life cycle, burst the host cells, starts infection into nearby cells. In severely infected patients, virus also affects the vital organs like the kidney and heart.

Prevalence, clinical characteristics, diagnosis and various strategies in the treatment and prevention of COVID-19 infection Since 31 December 2019 and as of 11th April 2020; 1,569,504 confirmed cases and deaths of 95,269 have been reported. Evidences suggest that human-to-human transmission occurs and the major route of transmission is respiratory droplets generated during infected through persons cough, sneezes or speaks, contact with articles contaminated with virus droplets; some reports suggest that transmission may occur through the digestive tract also [6]. Reproduction number (Ro) for COVID-19 in India is 1.4-3.9, which very close to that in Washington, California and China (3.28) [7]. The incubation period of the virus is 1-14 $\mathrm{d}$ which may increase up-to 19 $\mathrm{d}$ in asymptomatic carriers. The period from onset of symptoms to death may range from 6-41 $\mathrm{d}$ which depends upon the immunity and age of patient. Patients with coexisting medical conditions like hypertension, diabetes and cardiovascular disease have more fatality rates. The symptoms of COVID-19 are high fever, tiredness, dry cough, nasal congestion, runny nose, sore throat and diarrhea. Severity of symptoms may be mild, moderate or severe depending on the clinical features. Mild infection is manifested by the development of pneumonia or non-pneumonia whereas severe infection is manifested by dyspnea, acute respiratory distress syndrome, respiratory failure, septic shock and/or multiple organ dysfunction or failure $[8,9]$.

Clinical laboratory studies showed leucopenia and lymphopenia, which prime feature of COVID-19. In many patients, abnormal myocardial zymograms was observed due elevated level of lactate dehydrogenase and creatinine kinase, while in some patients, abnormal liver function with elevated alanine aminotransferase or aspartate aminotransferase was observed. Increased level of Creactive protein was noted with high erythrocytes sedimentation rate and D-dimer were also noted [10].

Cytokines and chemokines such as IL1B, interleukin-1 receptor antagonist (IL1RA), IL7, IL8, IL9, IL10, basic fibroblast growth factor, 
granulocyte colony-stimulating factor, granulocyte-macrophage colony-stimulating factor, interferon $\gamma$, IP10, MCP1, MIP1A, MIP1B, platelet-derived growth factor, tumor necrosis factor- $\alpha$, and vascular endothelial growth factor concentrations were higher in patients than in healthy adults. COVID-19 primarily targets respiratory system hence pneumonia, RNAnemia combined with incidence of patchy ground-glass opacities are observed and acute cardiac injury is also observed [11]

In vitro diagnostic assays were used for detection of COVID-19 infection which employs real-time reverse transcriptase polymerase chain reaction (RT-PCR). A wide range of serology immunoassays have also been developed that complement the molecular assays for the diagnosis of COVID-19 to increase sensitivity and decrease testing time. The most prominent IAs is automated chemiluminescent IA, manual ELISA, and rapid lateral flow IA, which detect the immunoglobulin $\mathrm{M}$ and immunoglobulin $\mathrm{G}$ produced in persons in response to SARS-CoV-2 infection [12].

There is no vaccine or specific drugs available in the market for prevention and treatment of infection caused by corona viruses. Because of time consuming process in the development of new drug, drug repurposing may be the only alternative no antiviral drug treatments have been approved; amongst the proposed treatment regimen is lopinavir/ritonavir $(400 / 100 \mathrm{mg}$ every $12 \mathrm{~h})$, chloroquine (500 mg every $12 \mathrm{~h}$ ), and hydroxychloroquine (200 mg every $12 \mathrm{~h}$ ). Alpha-interferon (e. g., 5 million units by aerosol inhalation twice per day) is used. Preclinical studies are going on testing the efficiency of remdesivir (GS5734) an inhibitor of RNA polymerase with in vitro activity against multiple RNA viruses [13].

In this study we have screened 19 drugs of various categories that may inhibit novel corona virus and also provide new insights for drug repurposing to scientist on compounds that may be effective. Subsequent validation of these drugs will be required to understand clinical efficacy for the treatment of infection caused by corona virus.

\section{MATERIALS AND METHODS}

Docking was performed with AutoDock 3.0.5 (Scripps Research Institute, USA). Docking to macromolecule was performed using an empirical free energy function and Lamarckian Genetic Algorithm, with an initial population of 250 randomly placed individuals and docking runs were performed for the ligand. Receptor preparation all 3-D crystal structures were obtained from the Brookhaven Protein Data Bank (http://www. rcsb. org/pdb). Receptors were prepared for docking in such a way that all heteroatoms (i.e., nonreceptor atoms such as water, ions, etc.) were removed. Kollmann charges were assigned. Solvation parameters were added to the final macromolecule structure using the Addsol utility of AutoDock. The In silico ADME study of different drugs was carried out using QikProp, Schordinger 9.0

\section{RESULTS}

Novel Corona viruses (nCOVID-19) belonging to a group of viruses that can infect humans and vertebrate animals. Especially it affects respiratory, central nervous and immune system of human and animals [14].

The present study was focused on main proteases (3CLpro/Mpro) in COVID-19 protein data bank ID 6LU7 (structured and deposited in protein data bank PDB) as potential target receptor for COVID-19 treatment. 6LU7 is the Mpro in COVID-19 shares 96\% similarity with the Mpro of the SARS-CoV $[15,16]$. Mpro is essential for the proteolytic maturation of virus and has been examined as a target protein to arrest the transmission from person to person which inhibits the breakdown of viral polyprotein [17]. The structure of 6LU7 provides a tool for identification of potential drug targets in treatment of COVID-19. Proteases inhibitors are the class of antiretroviral drugs which plays an important role in viral replication thus interruption in activity of proteases leads to arrest in viral replication thereby acts as potential targets for inhibiting replication in COVID-19 and often used as a protein target during the development of antiviral therapeutics [18].

Thus knowledge related to the molecular basis of COVID 19 provided potential drug targets for the discovery of less toxic, more selective drugs which may acts either of the step involved in the replication of viral genome. At present, considerable attention has been given on identifying and screening of currently available antiviral, antibacterial, anti-malerial and antitubercular drugs for the treatment of novel COVID-19 virus. Hence present research was focussed on docking of these drugs and in silico ADME studies by using the AutoDock program (Scripps Research Institute, USA). To determine the potential molecular target(s) as well as to support enzyme/receptor protein of anticovid activity of these compounds, the docking simulation was performed using 6LU7 receptor of covid.

19 different drugs were studied for binding to 6LU7 receptors and In silico ADME studies and the docking results are summarised in table 1 fig. $3 \mathrm{~A}$ and $3 \mathrm{~B}$.

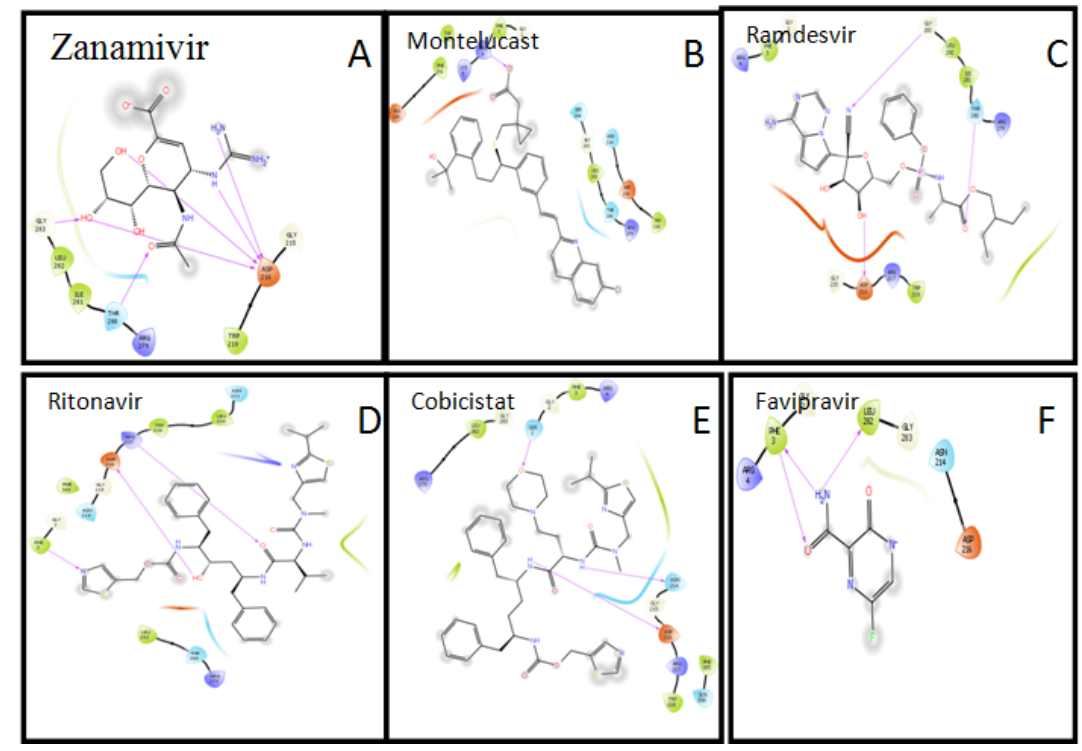

Fig. 3A: Structures and amino acids found in the active site pockets of 6LU7 of COVID-19 (A) Zanamivir-Active site-LEU282, ILE 281, THR280, ARG 279, TRP218, ASP216 (B) Montelucast-Active sites-SER 284, GLY 283, LEU 282, THR 280, ARG-279, ASN 214, ASP-216, TRP 218 C) Ramdesvir-Active sites GLY-215, ASP 216, TRP 216, GLY 283, LEU 282, THR 280, ARG-279, ILE 281 D) Ritonavir-Active sites-ASN221, LEU-220, TRP 218, ARG 217, ASP 216, GLY 215, ASN 214, LEU 282, THR 280 and ARG 279 E) Cobicistat-Active sites-ARG 279, LEU 282, GLY 283, ASN 214, ASP 216, ARG 217, TRP 218, F) Favipravir-Active sites-LEU 282, GLY 283, ASN 214, ASP 216 

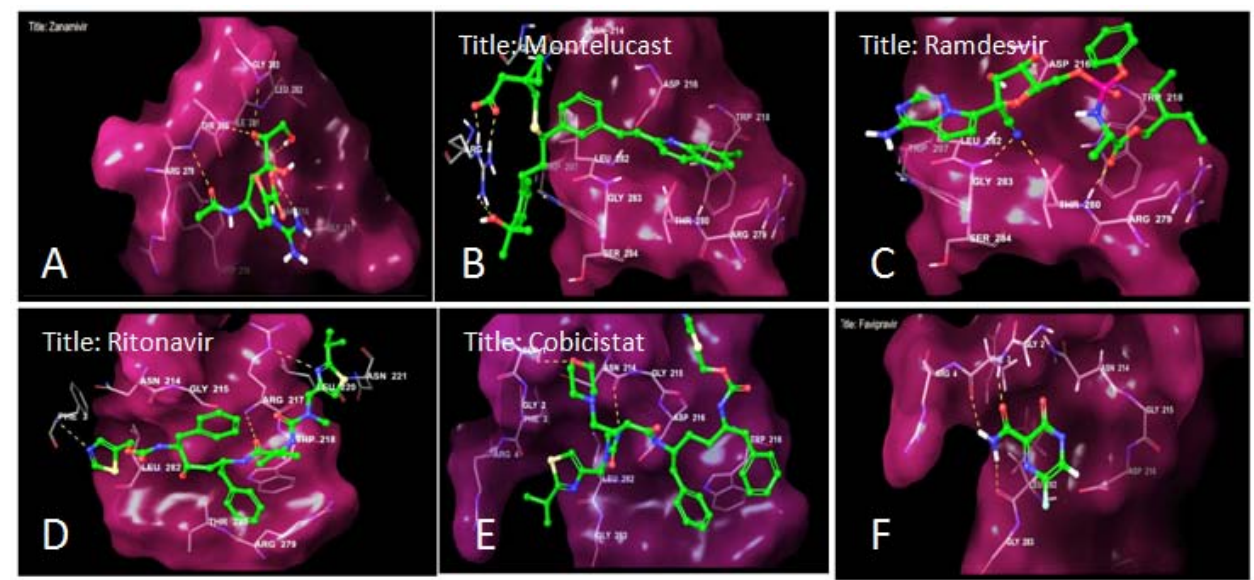

Fig. 3B: Docking analysis visualization of 6LU7 binding with nelfinavir (A) Zanamivir B) Montelucast C) Ramdesvir D) Ritonavir E) Cobicistat F) Favipravir

The results of docking analysis showed that zanamivir forms $\mathrm{H}-$ bonds with the 6LU7 amino acids LEU282, ILE 281, THR280, ARG 279, TRP218, ASP216 (B) Montelucast forms H-bonds with the 6LU7 amino acids SER 284, GLY 283, LEU 282, THR 280, ARG-279, ASN 214, ASP-216, TRP 218 C) Ramdesvir forms H-bonds with the 6LU7 amino acids GLY-215, ASP 216, TRP 216, GLY 283, LEU 282, THR 280, ARG-279, ILE 281 D) Ritonavir forms H-bonds with the 6LU7 amino acids ASN-221, LEU-220, TRP 218, ARG 217, ASP 216, GLY 215, ASN 214, LEU 282, THR 280 and ARG 279 E) Cobicistat forms H-bonds with the 6LU7 amino acids ARG 279, LEU 282, GLY 283, ASN 214, ASP 216, ARG 217, TRP 218, F) Favipravir forms H-bonds with the 6LU7 amino acids LEU 282, GLY 283, ASN 214, ASP 216. Al of the H-bonds interacted with amino acids in the COVID-19 6LU7 active site. The binding energy results are related to the number of $\mathrm{H}$-bonds formed with the active site pocket of COVID-19 Mpro.

Fig. $3 \mathrm{~A}$ shows structures and amino acids found in the active site pockets of 6LU7, the main protease (Mpro) found in COVID-19, which been structured and repositioned in PDB and can be accessed by the public, as of early March 2020. Ligands and variousl drug candidate have been selected based on adherence to Lipinski's rule of five. The selected ligands that did not incur more than 2 violations of Lipinski's rule could be used in molecular docking experiments with the target protein. The drug scanning results (Table. 1) show that all tested drugs follows Lipinski's rule of five.

These drugs showed maximum binding potential amongst 19 drugs hence selected for further studies. It was observed that Zanamivir with highest ligand-free energy score (docking score)-6.6 revealed highest binding potential of this drugs towards 6LU7 receptors of COVID-19. From generated docking model, zanamavir was bound to the active site of the enzyme as reported SARS-6LU7 receptor of COVID-19. The strong hydrogen bonding and hydrophobic interaction between zanamavir with the enzyme imply it as a potent 6LU7 inhibitor and could be a potential drug target for the treatment of COVID-19 infection.

Ramdesivir (GS-5734) is a nucleoside analogue which acts by inhibiting RNA-dependent RNA polymerase (RdRp). It produce its action by inhibiting viral nucleic acid synthesis and has not yet been approved by food and drug administration for its clinical use in any country. It has been used in United State for the diagnosis and treatment of SARS-CoV-2 patients and potential in the treatment of novel coronavirus infection [19]. Our molecular docking results revealed that it has high binding affinity for 6LU7 receptor of novel corona with a docking score of $(-3.524)$ as indicated in table 1

Table 1: Shows the molecular docking analysis results for several compounds against 6LU7, including binding energy/Gibbs Energy, ligand efficiency, inhibition constant, intermolecular energy, and van der Waals (VDW)-H Bond desolvation energy

\begin{tabular}{|c|c|c|c|c|c|c|c|c|c|c|c|c|c|}
\hline \multicolumn{2}{|c|}{ Criteria } & \multirow{2}{*}{$\begin{array}{l}\text { Glide } \\
\text { dock } \\
\text { score }\end{array}$} & \multicolumn{11}{|c|}{ In silico ADME by QikProp, Schordinger 9.0 } \\
\hline $\begin{array}{l}\text { S. } \\
\text { No } \\
\text {. }\end{array}$ & $\begin{array}{l}\text { Name and } \\
\text { structure of } \\
\text { drug }\end{array}$ & & $\begin{array}{l}\text { mol } \\
\text { MW }\end{array}$ & $\begin{array}{l}\text { QPlog } \\
\text { Po/w }\end{array}$ & $\begin{array}{l}\text { Violatio } \\
\text { n of } \\
\text { lipinski } \\
\text { 's rule } \\
\end{array}$ & $\begin{array}{l}\text { QPlog } \\
\text { S }\end{array}$ & $\begin{array}{l}\text { QPlog } \\
\text { HERG }\end{array}$ & $\begin{array}{l}\text { QPP } \\
\text { Caco }\end{array}$ & $\begin{array}{l}\text { QPP } \\
\text { MDCK }\end{array}$ & $\begin{array}{l}\text { QPlog } \\
\text { Khsa }\end{array}$ & $\begin{array}{l}\text { Huma } \\
\text { n oral } \\
\text { absor } \\
\text { ption }\end{array}$ & $\begin{array}{l}\text { Percent } \\
\text { human } \\
\text { oral } \\
\text { absorption }\end{array}$ & $\begin{array}{l}\text { Violation of } \\
\text { Jargan's } \\
\text { rule of } \\
\text { three } \\
\end{array}$ \\
\hline 1 & Zanamivir & -6.607 & 332.313 & -2.622 & 2 & -1.055 & -1.368 & 0.445 & 0.278 & -1.602 & 1 & 0 & 1 \\
\hline 2 & Montelucast & -4.606 & 586.187 & 9.396 & 2 & -10.792 & -6.303 & 139.277 & 206.303 & 1.982 & 1 & 94.416 & 1 \\
\hline 3 & Ramdesvir & -3.524 & 602.583 & 1.344 & 2 & -4.65 & -6.14 & 40.161 & 15.509 & -0.608 & 1 & 37.604 & 0 \\
\hline 4 & Ritonavir & -3.368 & 720.943 & 6.993 & 3 & -9.802 & -5.852 & 211.787 & 456.341 & 0.949 & 1 & 70.644 & 2 \\
\hline 5 & Ethambutol & -3.466 & 204.312 & -0.238 & 0 & 0.553 & -5.505 & 52.904 & 25.255 & -0.765 & 2 & 56.401 & 0 \\
\hline 6 & Cobistat & -3.417 & 776.023 & 6.339 & 3 & -7.918 & -6.205 & 58.529 & 140.356 & 0.787 & 1 & 56.819 & 2 \\
\hline 7 & Favipravir & -3.307 & 157.104 & -0.422 & 0 & -1.218 & -2.957 & 108.376 & 82.981 & -0.747 & 2 & 60.894 & 0 \\
\hline 8 & Ziduvudine & -2.944 & 267.244 & -0.015 & 0 & -1.399 & -4 & 48.906 & 18.954 & -0.903 & 2 & 57.093 & 0 \\
\hline 9 & Abacavir & -2.774 & 286.336 & 1.13 & 0 & -3.117 & -4.564 & 240.999 & 106.263 & -0.299 & 3 & 76.195 & 0 \\
\hline 10 & Isoniazid & -2.74 & 137.141 & -0.646 & 0 & -0.051 & -3.593 & 273.919 & 122.036 & -0.752 & 2 & 66.79 & 0 \\
\hline 11 & Maraviroc & -2.56 & 513.673 & 5.624 & 2 & -6.7 & -5.267 & 302.002 & 597.113 & 1.154 & 1 & 78.343 & 1 \\
\hline 12 & Saquinavir & -2.497 & 670.85 & 2.977 & 3 & -5.349 & -4.567 & 14.919 & 18.868 & -0.174 & 2 & 26.509 & 2 \\
\hline 13 & Lopinavir & -2.392 & 628.81 & 5.796 & 2 & -6.448 & -4.307 & 476.317 & 436.373 & 0.64 & 1 & 82.893 & 2 \\
\hline 14 & Ripivirine & -2.302 & 366.424 & 3.275 & 0 & -6.633 & -6.765 & 140.346 & 59.234 & 0.372 & 1 & 84.555 & 1 \\
\hline 15 & Nevirapine & -1.596 & 266.302 & 2.429 & 0 & -3.198 & -4.851 & $\begin{array}{l}1880.32 \\
3\end{array}$ & 978.955 & 0.056 & 3 & 100 & 0 \\
\hline 16 & Rifampin & -1.553 & 822.951 & 2.924 & 3 & -2.386 & -5.775 & 78.222 & 34.838 & -0.433 & 1 & 39.078 & 1 \\
\hline 17 & Etravirine & -1.523 & 435.282 & 2.607 & 0 & -6.307 & -6.217 & 61.773 & 42.831 & 0.195 & 1 & 74.26 & 1 \\
\hline 18 & Interferon & -1.233 & 376.669 & 3.883 & 0 & -3.829 & -3.45 & $\begin{array}{l}1312.81 \\
6\end{array}$ & 10000 & -0.052 & 3 & 100 & 0 \\
\hline 19 & Efavirenz & -0.885 & 315.679 & 3.571 & 0 & -5.112 & -4.601 & $\begin{array}{l}1568.27 \\
4\end{array}$ & $\begin{array}{l}6642.80 \\
3\end{array}$ & 0.281 & 3 & 100 & 0 \\
\hline
\end{tabular}


Ritonavir and lopinavir are mainly used as an antiretroviral drug to treat HIV-I infection in adults and children over $2 \mathrm{y}$ of age. Both these drugs act by inhibiting the replication of MERS-CoV and SARS$\mathrm{CoV}$. These drugs are recommended for the Coronavirus infected pneumonia diagnosis and treatment program. The docking result showed ritonavir's possible target for Clpro (6LU7) receptor with a dock score of-3.3 and-2.3, respectively (table 1).

Another drug Montelukast is cysteinyl leukotrienes receptor inhibitor (CysLT1) it acts by blocking the action of leukotriene D4 in the lungs resulting in decreased inflammation and relaxation of bronchial smooth muscle [20] thus may be helpful in preventing the inflammation associated with COVID-19 infection with a dock score of-4.6 (table 1).

\section{DISCUSSION}

There are no drugs available for the treatment of zoonotic corona virus. The transient nature of outbreak is the major reason behind the non-development of coronavirus inhibitors for the early preclinical and clinical trial to date.

Targeting 6LU7 gaining more importance in the treatment of COVID19 infection as it is one of the most important protease involved in viral replication [21]. In the present study an attempt has been made to suggest an in silico computational relationship between existing antiviral drugs, antimalarial and antitubercular drugs and Coronavirus main protease (6LU7) has been illustrated. Hence drug repurposing of approved drugs is the only option available for preventing the spread of infection. Most of these drugs are available in market with known toxicity, LogP, cell uptake and EC50 values etc. Their effects are already proven in preclinical studies. Hence To search for potential drug target for the treatment of corona virus, we screened 19 various drugs of different categories from protein data bank. The antiviral, anti-malarial, anti-tubercular, immunomodulators and cysteinyl leukotrienes receptor inhibitor exhibited high affinity towards 6LU7 receptor which is 3 chymotrypsin proteases responsible for inhibiting viral replication indicating their efficacy for treating SARS-CoV-2 [22].

In this study, it was observed that antiviral drugs ritonavir, lopinavir and saquinavir showed selective binding against viral protease as depicted in fig. $3 \mathrm{~A}$ and $\mathrm{B}$. The binding scores of the drug molecules on the COVID-19 was saquimzalfinavir >lopinavir> ritonavir respectively.

The most important cause of deaths in covid related disease is respiratory failure, which is progressive and unresponsive to treatment $[23,24]$. ARDS, which frequently occurs in these patients, is an acute inflammatory lung injury, a clinical condition that is not well understood due to its complex pathogenesis, and is a result of widespread alveolar injury caused by intense inflammation. IL- 6 and IL-8, the tumor necrosis factor (TNF) and IL-1 produced in the early phase and other pro-inflammatory cytokines that occur in the later stages of the disease, induce leukocyte migration to the region. Then, leukocytes accumulating in the lungs are activated and secretive reactive oxygen species and proteases that damage capillary endothelium and alveolar epithelium. Montelukast therapy has been shown in recent studies to reduce TNF- $\alpha$, IL-6 and IL-1b levels [23]. The pronounced inhibitory effect of montelukast against bradykinininduced tracheal smooth muscle contraction has also been demonstrated, which supports the interaction between bradykinin and leukotriene mediators [23, 24] and showed greater binding affinity to the viral protease as depicted in fig. $3 \mathrm{~A}$ as compared to antiviral and antitubercular as depicted in table 1.

\section{CONCLUSION}

Treatment of COVID-19 has been challenge due to the nonavailability of effective drug therapy. The currently available antiviral drugs for COVID-19 treatment primarily act on the enzyme protease (Mpro/3Clpro). In this study, we used several drugs for targeting 6LU7 Mpro/3Clpro protein, which showed prominent effects in its inhibition that may act as potential inhibitors of COVID19 Mpro. However, further research is necessary to investigate the potential use of these drugs, which can be given either alone or in combination for speedy, effective eradication of COVID-19.

\section{ABBREVIATIONS}

HCoV: Human Coronavirus, nCOVID-19: Novel corona, SARS-CoV: Severe Acute Respiratory Syndrome Coronavirus, MERS-CoV: Middle East Respiratory Syndrome coronavirus, ACE-2: Angiotensinconverting enzyme-2, ssRNA: Single-stranded RNA, IL1RA: Interleukin-1 receptor antagonist, RT-PCR: Real-time reverse transcriptase-polymerase chain reaction

\section{FUNDING}

Nil

\section{AUTHORS CONTRIBUTIONS}

All authors have contributed equally.

\section{CONFLICT OF INTERESTS}

Declared none

\section{REFERENCES}

1. World Health Organization. Coronavirus. Available from: https://www.who.int/emergencies/diseases/novel-coronavirus2019/events-as-they-happen [Last accessed on 28 Mar 2020].

2. World Health Organization. Q and A on coronaviruses (COVID19); Available from: https://www.who.int/news-room/q-adetail/q-a-coronaviruses. [Last accessed on 08 Apr 2020].

3. Coronavirus Wikipedia. Available from: https://enwikipedia.org.wiki/coronavirus. [Last accessed on 28 Mar 2020].

4. Wu A, Peng Y, Huang B. Genome composition and divergence of the novel coronavirus (2019-nCoV) originating in China. Cell Host Microbe. 2020;27(3):325-8. doi: 10.1016/j.chom.2020.02.001. PMID 32035028.

5. Shereen MA, Khan S, Kazmi A, Bashir N, Siddique R. COVID-19 infection: origin, transmission, and characteristics of human coronaviruses. J Adv Res. 2020;24:91-8. doi: 10.1016/j.jare.2020.03.005, PMID 32257431.

6. Chan JF, Yuan S, Kok KH, To KK, Chu H, Yang J, Xing F, Liu J, Yip CC, Poon RW, Tsoi HW, Lo SK, Chan KH, Poon VK, Chan WM, Ip JD, Cai JP, Cheng VC, Chen H, Hui CK, Yuen KY. A familial cluster of pneumonia associated with the 2019 novel coronavirus indicating person-to-person transmission: a study of a family cluster. Lancet. 2020;395(10223):514-23. doi: 10.1016/S01406736(20)30154-9, PMID 31986261.

7. Ranjan R. Predictions for covid-19 outbreak in India using epidemiological models; 2020. Available from: https://www.medrxiv.org/content. [Last accessed on $12 \mathrm{Apr}$ 2020].

8. Unhale S, Ansar Q, Sanap S. A review on coronavirus (COVID19). WJPLS. 2020;6:109-15.

9. World Health Organization. Q and A on coronaviruses (COVID19). Available from: https://www.who.int/news-room/q-adetail/q-a-coronaviruses. [Last accessed on 08 Apr 2020].

10. Syed F, Yu Q. Cofilin, an intracellular marker for HIV-associated CD4 T-cell motility dysregulation, shed light on the mechanisms of incomplete immune reconstitution in the patients with HIV. J Med Virol. 2020;92(1):1-3. doi: 10.1002/jmv.25577. PMID 31502247.

11. Huang C, Wang Y, Li X, Ren L, Zhao J, Hu Y, Zhang L, Fan G, Xu J, Gu X, Cheng Z, Yu T, Xia J, Wei Y, Wu W, Xie X, Yin W, Li H, Liu M, Xiao Y, Gao H, Guo L, Xie J, Wang G, Jiang R, Gao Z, Jin Q, Wang J, Cao B. Clinical features of patients infected with 2019 novel coronavirus in Wuhan, China. Lancet. 2020;395(10223):497506. doi: 10.1016/S0140-6736(20)30183-5, PMID 31986264.

12. Vashist SK. In vitro diagnostic assays for COVID-19: recent advances and emerging trends. Diagnostics (Basel). 2020;10(4):202. doi: 10.3390/diagnostics10040202, PMID 32260471.

13. Cascella M, Rajnik M, Cuomo A. Features, evaluation and treatment coronavirus (COVID-19); 2020. Available from: https://www.ncbi.nlm.nih.gov/books/NBK554776/. [Last accessed on 08 Apr 2020].

14. $\mathrm{Xu}$ J, Zhao S, Teng T. Systematic comparison of two animal-tohuman transmitted human coronaviruses: SARS-CoV-2; 2020. 
15. Zhavoronkov A, Aladinskiy V, Zhebrak A. Potential 2019-nCoV 3C-like protease inhibitors designed using generative deep learning approaches. Vol. 1. 2020. doi: 10.26434/ CHEMRXIV.11829102.

16. Xu Z, Peng C, Shi Y. Nelfinavir was predicted to be a potential inhibitor of 2019-nCov main protease by an integrative approach combining homology modelling, molecular docking and binding free energy calculation. 2020;1201:1-2.

17. Liu R, Zhang B, Jin Z. The crytal structure of 2019-nCoV main protease in complex with an inhibitor. Vol. N3; 2020

18. Chang KO, Kim Y, Lovell S, Rathnayake AD, Groutas WC. Antiviral drug discovery: Norovirus proteases and development of inhibitors. Viruses. 2019;11(2):1-14. doi: 10.3390/v11020197, PMID 30823509.

19. Holshue ML, DeBolt C, Lindquist S, Lofy KH, Wiesman J, Bruce H, Spitters C, Ericson K, Wilkerson S, Tural A, Diaz G, Cohn A, Fox L, Patel A, Gerber SI, Kim L, Tong S, Lu X, Lindstrom S, Pallansch MA, Weldon WC, Biggs HM, Uyeki TM, Pillai SK, Washington State 2019-nCoV Case Investigation Team. First case of 2019 novel coronavirus in the United States. N Engl J Med. 2020;382(10):929-36. doi: 10.1056/NEJMoa2001191, PMID 32004427.

20. Brooks CD, Summers JB. Modulators of leukotriene biosynthesis and receptor activation. J Med Chem.
1996;39(14):2629-54. doi: 10.1021/jm960088k, PMID 8709092.

21. Peele KA, Potla Durthi C, Srihansa T, Krupanidhi S, Ayyagari VS, Babu DJ, Indira M, Reddy AR, Venkateswarulu TC. Molecular docking and dynamic simulations for antiviral compounds against SARS-CoV-2: A computational study. Inform Med Unlocked. 2020;19:100345. doi: 10.1016/j.imu.2020.100345.

22. Kartik M, Prasanth G, Sushank A. Dual inhibitors of SARS-CoV-2 proteases: pharmacophore and molecular dynamics based drug repositioning and phytochemical leads. J Biomol Struct Dyn. 2020;39(4):1-14.

23. Zhang JJ, Dong X, Cao YY, Yuan YD, Yang YB, Yan YQ, Akdis CA Gao YD. Clinical characteristics of 140 patients infected with SARS-CoV-2 in Wuhan, China. Allergy. 2020;75(7):1730-41. doi: 10.1111/all.14238, PMID 32077115.

24. Chen $X$, Zhang $X$, Pan J. Effect of montelukast on bronchopulmonary dysplasia (BPD) and related mechanisms. Med Sci Monit. 2019 Mar 13;25:1886-93. doi: 10.12659/MSM.912774, PMID 30862773.

25. Sarzi Puttini PP, Giorgi V, Sirotti S, Marotto D, Ardizzone S Rizzardini G, Antinori S, Galli M. COVID-19, cytokines and immunosuppression: what can we learn from severe acute respiratory syndrome? Clin Exp Rheumatol. 2020;38(2):33742. PMID 32202240. 